\title{
A Historical Look at Indian Healthcare Professionals in the NHS
}

\author{
Balmukund Bhala ${ }^{1}$, Aruna Bhala ${ }^{2}$, Neeraj Bhala ${ }^{3}$ \\ 1 Consultant Anaesthetist, Wellingborough \\ 2 Community Paediatrician, Northampton General Hospital \\ 3 Consultant Gastroenterologist, Queen Elizabeth Hospital, University of Birmingham NHS \\ Foundation Trust, Birmingham \\ balmbhala@yahoo.co.uk
}

Key words

NHS, Indian, Healthcare professionals, contribution

cite as: Bhala B, Bhala A \& Bhala N. A Historical look at Indian healthcare professionals in the NHS. Sushruta 2019 (Nov) 19-21 DOI: 10.38192/12.1.10

Doctors and nurses from the Indian subcontinent have been working in the UK healthcare sector for over a 100 years. Initially only open to Europeans, Indians were allowed to enter the Indian Medical Service (IMS) in 1855, although the requisite was that they had to sit exams based in London and had to be registered with the General Medical Council (GMC). At the time there were many schools training Indian doctors, but only as licentiates. In relation to medical education, through pressure applied by the IMS, indigenous courses for the training of Indian doctors were abolished and several medical colleges, modelled along western pedagogic styles, were established. The staff of all these colleges were appointed from the IMS and their methods of instruction were virtually indistinguishable from those practised in England and Scotland. Indian degrees were recognised in 1892 by the GMC and this recognition persisted until 1975, with a short interlude in the mid-1930s when there was a dispute between the GMC and the Government of India about the quality of Indian medical education. ${ }^{1}$

However, the development of medical practice in India did not follow the pattern that should integrate indigenous practice with 'western medicine' and they should not be over reliant on medically trained professionals, relying instead on medical assistants and health workers who did not have to undertake a full-fledged medical training. The emigration of Indian doctors, the failure to produce a coherent medical policy, and the absence of public-health medicine and health facilities in rural areas meant that Indian degrees were quite suitable for working in England, but probably totally irrelevant for working to the benefit of the vast majority of the Indian population. ${ }^{1}$ It is estimated that by 1945 there were 'no less' than 1000 Asian doctors throughout Britain, 200 of them in London alone and most of them working in primary care. In 1960, Enoch Powell, Health Secretary took the lead to change the immigration policy in order to meet the workforce demands of the NHS. Improved immigration policy helped, amongst others, Indian doctors and nurses to study further and progress to more secure jobs. 2 
In the 60 s and 70s, many internationally recruited healthcare workers faced open racism and discrimination often leading to repetitive failures in examinations and stunted career progression. A TV comedy series 'The Indian Doctor' portrayed the challenges faced by Indian healthcare professionals working in remote communities 3 . It is also true that many doctors were also probably influenced by the 'Gandhian philosophy' of service to the benefit of humanity without personal rewards. This is perhaps why many doctors also ended up in deprived areas and became involved in local politics. At the end of the 1970s, the Royal Commission on the NHS 2 estimated that between 18,000-20,000 registered doctors in the UK were born outside the UK, with half of these being from India or Pakistan. A 2005 report found that in $2003,29 \%$ of NHS doctors were foreign-born and that $44 \%$ of nurses recruited to the NHS after 1999, were born outside the UK.

As the gaps existed in unpopular areas or 'hard to fill' specialities, they were allowed to work in inner cities or remote areas as well as district general hospitals. There was already an official acknowledgement of the roles that these overseas doctors were playing. In a debate in the House of Lords in 1961, Lord Cohen of Birkenhead commented on the fact that: 'The Health Service would have collapsed if it had not been for the enormous influx from junior doctors from such countries as India and Pakistan.' 4

Lord Taylor of Harlow in the same debate said:

'They are here to provide pairs of hands in the rottenest, worst hospitals in the country because there is nobody else to do it.'

Although it is useful to understand immigration from the point of view of the state, it is also important to acknowledge that, much like the late 19th and early 20th century, because of the links that have already been described, many overseas qualified doctors had a personal desire to come to England to improve their clinical training, to work in the great institution of the NHS, and to pick up skills that they would then take home. Many of course chose to immigrate permanently, but the most common reason for coming was to obtain skills and then go back. Even to this day the premium of British experience continues to play well particularly in the private medical sector in many Commonwealth countries. But what was clear from the outset was that both the jobs and the experience available to this influx of immigrant doctors were going to be severely restricted. Over half of migrant doctors were disappointed with their experience of working and studying in this country. ${ }^{5}$ So they ended up being tied to the UK and the NHS, because returning without fulfilling their aspirations was not an option.

The experience of the International Medical Graduates (IMGs) and nurses included themes such as, the devaluation, self-blame, discrimination/lack of equal opportunity, invisibility, experiencing fear and tolerated such behaviour for fear of being thrown out with their families. As the primary motivation was to provide an excellent service to their patients rather than seek recognition or fame, the contribution of many doctors and nurses of Indian origin were forgotten and lost in the NHS. Frustrations grew and interviews revealed some common 
themes for dissatisfaction such as; feeling devalued and deskilled and perceptions of racial discrimination, not feeling personally or professionally valued and unmet expectations. ${ }^{6,7}$

Migrant doctors were more likely to become GPs against their inclination, and more likely to be practising in a speciality that was not their first choice. They were also more likely to feel that they had progressed more slowly in terms of postgraduate training and experience. These included the policy of rotating posts at teaching hospitals. This may also apply to vocational training schemes. ${ }^{5}$ Working at a teaching hospital helped in the fostering of vital informal networks which could greatly influence a young doctors entry into the key areas of many specialties. Having trained outside of Britain migrant doctors were more likely not to have cultivated a reputation in a British teaching hospital from which rotational opportunities tended to arise.

Despite such negative experiences participants indicated that the experiences gained whilst working in the NHS were useful. IMGs who wanted to see the NHS and the general working environment improve, took active parts in meetings of British Medical Council (BMA) and the GMC. A need was felt to have an Indian associations of doctors in different regions of UK, hence organisations like Overseas Doctors Association (ODA), Indian Medical Association (IMA-UK) were conceived. In parallel other organisations sprung up from Hindu International Medical Mission to Sewa International, BAPIO to Global Association of Physicians of Indian Origin (GAPIO), as a way to represent the Indian doctors globally.

NHS is celebrated by the politicians and public alike as a great British institution, yet from its inception it has been crafted and nurtured by the contribution of a significant number of international medical and nursing graduates. Incorporating narratives from migrant healthcare workers into general histories of the NHS would give us a more holistic understanding of the past and a different perspective on the present. It is in this sense that one would argue for a need to broaden understanding of who the 'architects' of the NHS were. NHS is an evolving organisation brought into existence by the actions of thousands of people, many of whom were migrants, rather than as a monolithic structure established by politicians and civil servants in the immediate aftermath of World War II. Approaching the history of the NHS from such an angle could lead to a better understanding of what impact migration might have had on the development of healthcare in Britain. Is the daily practice of psychiatry in Britain influenced by the fact that the specialty employed hundreds of practitioners trained in the Indian subcontinent? To what extent has engagement with ethnic minority patients been shaped by the presence of migrants in the NHS workforce? Our inability to provide detailed answers to such questions is a major gap in our understanding of how the NHS evolved. ${ }^{1,9}$

As NHS enters its seventh decade and a new 10-year strategy is revealed, there needs to be a greater understanding and acknowledgement of the huge contribution of international medical and nursing workforce in the shaping of the future of this country. In 2018, as NHS turned 70, the Royal College of General Practitioners (RCGP) exhibition has attempted to 
highlight the contribution of IMGs (many from the Indian subcontinent) as architects and lifeblood of NHS and primary care provision in the UK.

We now understand that healthcare migration has mutual benefit to both countries of origin as well as adopted lands. This is evident in USA, Canada, Africa, Australia and New Zealand through further emigration/immigration. Medical immigration also expanded beyond medical world as many doctors brought with them, through their leadership, wider cultural concepts of spirituality and alternative practices (i.e. acupuncture, yoga, pranayama) to better health of the nation. Our next steps includes recognising the role of women from within the UK and amongst migrants, in the NHS. ${ }^{8}$ The Interim NHS People Plan needs to understand the aspirations and well-being for staff across boundaries and find sustainable solutions to continue to provide for the wide-ranging aspirations of the NHS Long term plan. Political leaders need to decide on the narrative for educating the public on the contribution of migrant health workers and crucial role they play in providing excellent care. NHS Employers and regulatory bodies need to clean up their acts in providing culturally sensitive support, demonstrate emotional intelligence and provide equal opportunities to reach one's potential. Brexit effect might create more opportunities in near future, if recent visa problems could be handled properly. The UK, as we know it today, is to a great extent the result of population movement. Migrants do not just bring a colourful presence, different cultures, music and food but shape nations by working in industry, public services and becoming involved in civil society. ${ }^{10}$

NHS is a role model for other countries including India are aspiring to. Evidence of that is seen in some reverse migration to India. Hopefully other countries will benefit from excellent leadership and patient safety experience in NHS. Our problems of the past are diminishing but new problems might replace them and we need to identify them so we could tackle them head on. Organisations such as BAPIO have a huge leadership role to play in the present and future of the NHS. We would like to remind our readers what Swami Vivekananda advised our next generations: 'Not to forget our Indian roots, with our spirituality as the base!'

\section{References}

1. Esmail A. Asian doctors in the NHS: service and betrayal. Br J Gen Pract. 2007 Oct;57(543):827-34. PMID: 17925142; PMCID: PMC2151817.

2. Royal Commission on the NHS, Sub-Committee B Overseas Doctors, Note by the Secretariat (no date). BS 6 /3573, National Archives, Kew.

3. Avatar Productions, Bang Post Production (post-production), Rondo Media. The Indian Doctor (2010-). Distributors; British Broadcasting Corporation (BBC) (2010) (UK) (TV)

4. Kyriakides C, Virdee S. Migrant labour, racism and the British National Health Service. Ethn Health. 2003;8(4):283-305.

5. Smith D. Overseas doctors in the National Health Service. London: Policy Studies Institute; 1980. 
6. Nichols J 1 , Campbell J. The experiences of internationally recruited nurses in the UK (1995-2007): an integrative review. J Clin Nurs. 2010 Oct;19(19-20):2814-23. doi: 10.1111/j.1365-2702.2009.03119.x.

7. Alexis $O 1$, Vydelingum $V$, Robbins I. Engaging with a new reality: experiences of overseas minority ethnic nurses in the NHS. J Clin Nurs. 2007 Dec;16(12):2221-8.

8. Fiona Johnson: Diversity within diversity: Nuffield Trust, 2018

9. Simpson JM, Esmail A, Kalra VS, Snow SJ. Writing migrants back into NHS history: addressing a collective amnesia\&\#39; and its policy implications. J R Soc Med. 2010;103(10):392-396. doi:10.1258/jrsm.2010.100222

10. Johnson MRD, McGee P. Globalising care. Diversity in Health and Social Care 2005;2:1- 